\title{
Dimers as Fast Diffusing Species for the Aggregation of Oxygen in Boron-Doped Czochralski Silicon: Formation of New Thermal Donors
}

\author{
Besma Moumni $^{1,2}$, Abdelkadr Ben Jaballah ${ }^{1,2 *}$, Selma Aouida, Brahim Bessaïs ${ }^{1}$ \\ ${ }^{1}$ Photovoltaic Laboratory, Research and Technology Centre of Energy (CRTEn), Borj Cédria Technopark, Hammam Lif, Tunisia; \\ ${ }^{2}$ Department of Physics, Samtah Faculty of Science and Arts, Jazan University, Jazan, KSA. \\ Email: "gadour2003@yahoo.fr
}

Received July $26^{\text {th }}, 2011$; revised August $30^{\text {th }}, 2011$; accepted September $10^{\text {th }}, 2011$

\begin{abstract}
The thermal behaviors of oxygen-related complexes in boron doped Czochralski Silicon (Cz-Si) wafers at $450^{\circ} \mathrm{C}$ and $800^{\circ} \mathrm{C}$ were investigated using Fourier transform infrared spectroscopy (FTIR) and Hall mobility measurements. Activation of thermal donors (TDs) at $450^{\circ} \mathrm{C}$ leads to a decrease of both mobility and majority carrier concentration using the four point probes configuration of Van Der Pauw. It was found that annealing at $450^{\circ} \mathrm{C}$ would possibly affect the electronic properties of the $\mathrm{Si}$ wafers via the formation of interstitial di-oxygen defects $\left(\mathrm{IO}_{2 \mathrm{i}}\right)$, which exhibit an IR absorption band positioned at $545 \mathrm{~cm}^{-1}$. A strengthening of the IR bands peaking at around $1595 \mathrm{~cm}^{-1}, 1667 \mathrm{~cm}^{-1}, 1720$ $\mathrm{cm}^{-1}$ and $1765 \mathrm{~cm}^{-1}$ occurs at $450^{\circ} \mathrm{C}$, while they disappear at $800^{\circ} \mathrm{C}$. At high temperatures, the precipitation of interstitial oxygen becomes predominant over all other oxygen-related reactions. The dynamic of oxygen-thermal donor generation-annihilation in $\mathrm{Cz}$-Si involving the formation of small oxygen clusters is discussed.
\end{abstract}

Keywords: Cz-Silicon; Infrared Spectroscopy; Interstitial Oxygen; Thermal Donors; Oxygen Vacancies; Oxygen Dimers; Oxygen Aggregation

\section{Introduction}

During the Czochralski (CZ) growth of silicon ingots, oxygen is incorporated into the crystal as an electrically inactive interstitial defect $\left(\mathrm{O}_{\mathrm{i}}\right)$, in major part due to the partial dissolution of the quartz crucible. Usually, interstitial oxygen may form small electrically active agglomerates commonly called thermal donors (TDs) at temperatures ranging between $350^{\circ} \mathrm{C}$ and $500^{\circ} \mathrm{C}$ [1], which have a detrimental effect in device processing and operation. It is suggested that single interstitial oxygen $\left(\mathrm{O}_{\mathrm{i}}\right)$ may become substitutional oxygen $\left(\mathrm{O}_{\mathrm{s}}\right)$ if it combines with a mobile vacancy $(\mathrm{V})$ producing a vacancy-oxygen complex (VO) [2,3]. The VO complex is called off-center substitutional oxygen, or the A-center, and consists of bridging oxygen with a pair of Si neighbors of the vacancy. The VO-type complexes are also accounted as oxygen-related thermal donors [3], since they can induce a shallow donor level into the silicon band-gap, then compensating the electrical effect of the majority carriers. Despite all research efforts, the detailed formation mechanisms of TDs in silicon crystals still remain not well understood, and therefore there is no complete model that

${ }^{*}$ Corresponding author. could account for all experimental data.

An attempt to understand the dynamic of oxygen-thermal donor generation-annihilation in $\mathrm{Cz}-\mathrm{Si}$ is presented. Following the process developed in this work, a thermal treatment at $450^{\circ} \mathrm{C}$ leads to the formation of small oxygen clusters that introduce a shallow donor level in the semiconductor band gap. Hall Effect measurements show that a successive thermal treatment at $800^{\circ} \mathrm{C}$ reduces the donor concentration. In this work, the radial variation of $\left[\mathrm{O}_{\mathrm{i}}\right]$ and TDs in $\mathrm{Cz}-\mathrm{Si}$ wafers, determined by FTIR spectroscopy, is taken as a key point to explain the disappearing of some TDs and $\mathrm{VO}$ complexes while annealing at high temperatures $\left(>600^{\circ} \mathrm{C}\right)$, and hence to try clarifying their dependence on interstitial oxygen concentration. The electrical activity of oxygen related TDs and the resulting compensation phenomenon are claimed basing on a series of resistivity and Hall Effect measurements. These results enable conceiving efficient treatments that may overcome photo-degradation due to related boronoxygen defects, then improving the quality of solar grade Czochralski silicon.

\section{Experimental}

In this study, we used both solar and electronic grade 
boron-doped p-type monocrystalline $\mathrm{CZ} \mathrm{Si}$ wafers, having a resistivity in the ranges of $1-2 \Omega \cdot \mathrm{cm}$ and $7-8 \Omega \cdot \mathrm{cm}$, respectively. The concentration of the interstitial oxygen $\left(\mathrm{O}_{\mathrm{i}}\right)$ was evaluated by means of FTIR spectroscopy using the well-known absorption band at $1107 \mathrm{~cm}^{-1}$ using the IOC88 calibration factor of $3.14 \times 10^{17} \mathrm{~cm}^{-2}$ [4]. The various oxygen complexes forming in $\mathrm{Cz}$-Silicon are determined using a Nicolet instrument Magna system 550 Spectrometer having a resolution of $4 \mathrm{~cm}^{-1}$. Moreover, it is found that the substitutional carbon concentrations are less than $5 \times 10^{15} \mathrm{~cm}^{-3}$ of the adjacent samples subjected to thermal treatments. In order to study the formation of oxygen-related defects, $\mathrm{Cz}$-Si samples were heat treated at $450^{\circ} \mathrm{C}$ and $800^{\circ} \mathrm{C}$ during 4 hours in a closed tubular furnace using tungsten-halogen lamps under nitrogen ambient. Clustering of oxygen atoms occurs, resulting in the formation of different oxygen complexes from small clusters like dimer $\left(\mathrm{O}_{2 \mathrm{i}}\right)$, interstitial-dioxygen centre to oxygen-related thermal donors (TDs). The resistivity and the Hall Effect measurements were carried out using the four point probes and the Van Der Pauw methods at a current density and a magnetic field of about $100 \mu \mathrm{A}$ and $0.15 \mathrm{~T}$, respectively.

\section{Experimental Results and Discussions}

\subsection{Interstitial Oxygen and Oxygen-Related Complexes in Cz-Silicon}

Figure 1(a) depicts the FTIR spectra of as-grown $\mathrm{Cz}-\mathrm{Si}$ samples at two interstitial oxygen concentrations. The main IR absorption band of interstitial oxygen appears at around $1100 \mathrm{~cm}^{-1}$. Roughly as-grown Si wafers contain $10^{18}$ oxygen atoms $/ \mathrm{cm}^{3}$. However, growth conditions lead to the formation of a variety of TDs and oxygen-related complexes during the cool-down process. Is bonded with two silicon atoms and accordingly all four dangling bonds are passivated. The local vibration modes of $\mathrm{VO}_{2}$ thus consist basically of the LV frequencies of two separate VO's modified by the interactions between the oxygen atoms: an asymmetric stretching mode is observed at $889 \mathrm{~cm}^{-1}$. As the number of oxygen atoms surrounding the core of the preliminary formed oxygen-vacancy complexes increases and became more stable, the local vibration modes of $\mathrm{VO}_{3}$ shift to high frequency as regard to $\mathrm{VO}_{2}$; an asymmetric stretching mode appears at $966 \mathrm{~cm}^{-1}$. The inset of Figure 1(b) indicates the various vibration modes in the $400-600 \mathrm{~cm}^{-1}$ spectral region; the band at 566 $\mathrm{cm}^{-1}$ is associated to the oxygen-dimer $\left(\mathrm{O}_{2 \mathrm{i}}\right)$ [5], while the band at $512 \mathrm{~cm}^{-1}$ is assigned to symmetric stretching of interstitial oxygen and the other vibration modes are related to oxygen TDs. The vibration modes located at $484 \mathrm{~cm}^{-1}$ and $505 \mathrm{~cm}^{-1}$ seem to appear only for $\left[\mathrm{O}_{\mathrm{i}}\right]$ exceeding $0.9 \times 10^{18} \mathrm{~cm}^{-3}$. This result would signify that activation of some vibration modes depend on interstitial oxygen concentration, and probably on the spatial distribution of interstitial oxygen atoms. Figure 2 clearly shows that $\mathrm{VO}_{2}$ concentration is less sensitive to $\left[\mathrm{O}_{\mathrm{i}}\right]$ than $\mathrm{VO}$ and $\mathrm{VO}_{3}$, with a minimum higher than all $\mathrm{VO}_{\mathrm{n}}$ concentrations. However, generation of TDs, $\mathrm{VO}$ and $\mathrm{VO}_{3}$ depend on $\left[\mathrm{O}_{\mathrm{i}}\right]$. Basically, IR bands in the $600-400 \mathrm{~cm}^{-1}$ and $1200-700 \mathrm{~cm}^{-1}$ spectral range (Figure 1), clearly reveal that even under the cool down process, the generation of TDs is strongly mediated by the formation of oxygen dimer rather than $\left[\mathrm{O}_{\mathrm{i}}\right]$. This observation indicates that dimer formation is rate limiting step for the built of small clusters behaving as TDs at low temperatures.

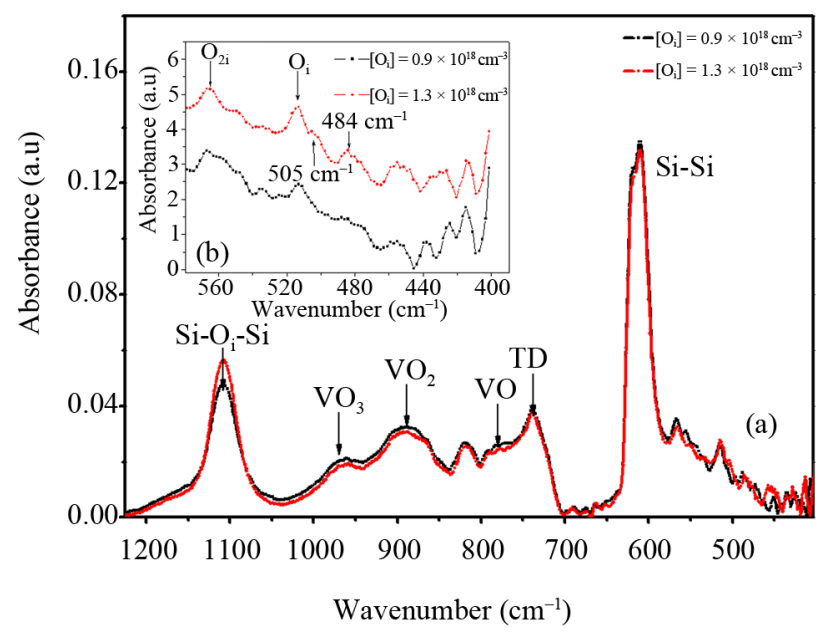

Figure 1. FTIR spectra at $300 \mathrm{~K}$ of as-grown $\mathrm{Cz}$-Si samples for $\left[O_{i}\right]=0.9 \times 10^{18} \mathrm{~cm}^{-3}$ (squared symbol) and $\left[O_{i}\right]=1.3 \times$ $10^{18} \mathrm{~cm}^{-3}$ (circle symbol). The discrepancy is induced by the temperature gradient during the cool-down process. The inset shows details of IR bands in the $400-600 \mathrm{~cm}^{-1}$ spectral range.

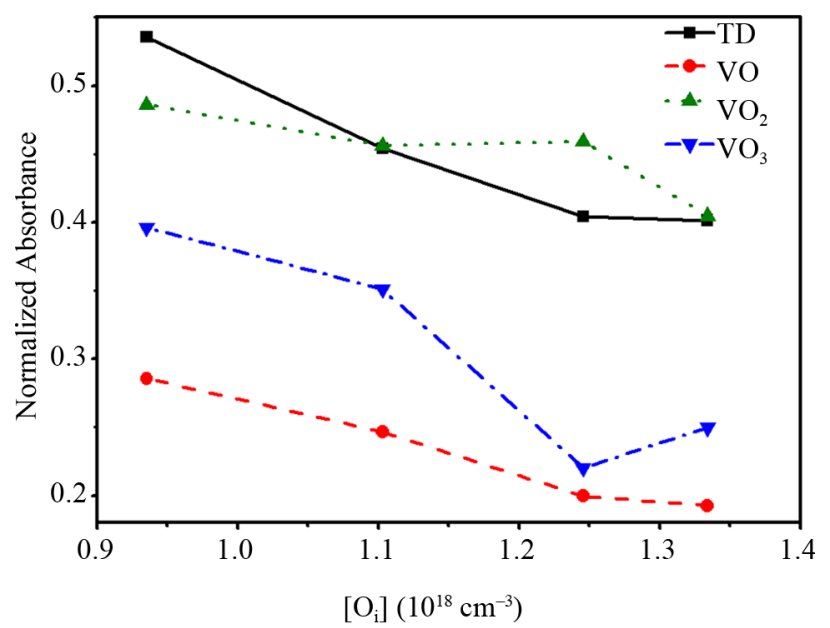

Figure 2. Room temperature FTIR absorbance intensity related to TDs (appearing at $736 \mathrm{~cm}^{-1}$, squared symbol), VO (circle), $\mathrm{VO}_{2}$ (up triangle), and $\mathrm{VO}_{3}$ (down triangle) complexes versus $\left[\mathrm{O}_{i}\right]$ in as-grown $\mathrm{Cz}-\mathrm{Si}$. 
Figure 3 shows the variation of the mobility and the majority charge carrier concentration versus interstitial oxygen concentrations. We pointed out slightly higher resistivity (about $1 \Omega \cdot \mathrm{cm}$ more) in Si wafers with low $\left[\mathrm{O}_{\mathrm{i}}\right]$. The majority carrier concentration exhibits similar tendencies as $\left[\mathrm{O}_{\mathrm{i}}\right]$. The majority carrier mobility was found to increase from 191 to $381 \mathrm{~cm}^{2} \cdot \mathrm{V}^{-1} \cdot \mathrm{s}^{-1}$ with increasing $\left[\mathrm{O}_{\mathrm{i}}\right]$. Hence, oxygen-vacancy complexes behave like TDs and accumulation of impurities and defects could be responsible of the low carrier mobility. The effects of TDs and oxygen-related defects are lower in region of high oxygen concentrations.

\subsection{Generation and Annihilation of TDs}

Formation and annihilation of TDs and oxygen-point like defects are well known to be thermal-dependent processes [6]. A quantitative comparison of the free carrier concentrations before and after annealing at $450^{\circ} \mathrm{C}$ and subsequently at $800^{\circ} \mathrm{C}$ let us draw some qualitative conclusions about the relationship between the majority charge carrier and oxygen aggregation. Our study was focused on some bands, which were affected by annealing at $450^{\circ} \mathrm{C}$ and successive annealing at $800^{\circ} \mathrm{C}$, exhibiting weak absorption in the $1800-1300 \mathrm{~cm}^{-1}$ and $600-400 \mathrm{~cm}^{-1}$ spectral ranges. The FTIR absorption modes relative to thermal generation of new TDs in the $1200-700 \mathrm{~cm}^{-1}$ spectral range are not observed due to an overlap of the absorption bands belonging to interstitial oxygen and oxygenvacancy complexes $\left(\mathrm{VO}_{\mathrm{n}}\right)$.

In Figure 4, the effect of oxygen aggregation in $\mathrm{Cz}$ silicon treated at $450^{\circ} \mathrm{C}$ is correlated with a group of infrared absorption bands at $566 \mathrm{~cm}^{-1}, 545 \mathrm{~cm}^{-1}$ and 517 $\mathrm{cm}^{-1}$. Dimer vibration band at $566 \mathrm{~cm}^{-1}$ grows up and broadens giving rise to a new band located at around 545 $\mathrm{cm}^{-1}$. The loss of interstitial oxygen atoms successive to annealing at $450^{\circ} \mathrm{C}$ is due to the increase of oxygen dimer concentration and to a novel oxygen-related defect [7] having an IR absorption mode around $545 \mathrm{~cm}^{-1}$. After annealing at $450^{\circ} \mathrm{C}$, the IR bands related to $\mathrm{VO}_{2}$ and $\mathrm{VO}_{3}$ defects are still stable, while VO shows a slight absorbance decrease (Figure 5). Thermal annealing at $800^{\circ} \mathrm{C}$ decreases the $\left[\mathrm{O}_{2 \mathrm{i}}\right]$ that becomes comparable to that of the as-grown sample. The formation of the interstitial oxygen pairs as well as the development of oxygen-point like defects $\left(\mathrm{VO}_{\mathrm{n}}\right.$ and $\mathrm{IO}_{2 \mathrm{i}}$ complexes), play an important role in understanding aggregation. When the interstitial oxygen atoms approach each other to form the $\mathrm{O}_{2 \mathrm{i}}$ dimer in a staggered or skewed $\mathrm{O}_{\mathrm{i}}-\mathrm{Si}-\mathrm{Si}-\mathrm{O}_{\mathrm{i}}$ configuration $[5,8,9]$, the mutual interactions between the $\mathrm{O}_{\mathrm{i}}$ 's cause splitting and shift in the local vibration frequencies of $\mathrm{O}_{\mathrm{i}}$. Figure 6 shows that the IR bands located at $1595 \mathrm{~cm}^{-1}, 1667 \mathrm{~cm}^{-1}$, $1720 \mathrm{~cm}^{-1}$ and $1765 \mathrm{~cm}^{-1}$ strengthen following annealing at $450^{\circ} \mathrm{C}$, while they weaken after subsequent annealing at $800^{\circ} \mathrm{C}$. At elevated temperatures $\left(>700^{\circ} \mathrm{C}\right)$ the formation of new TDs and nucleation sites that start oxygen precipitation become predominant and are associated with a loss of $\mathrm{O}_{\mathrm{i}}$ atoms, as indicated in Figure 5.

Yong Lee et al. suggest that long oxygen chains can be developed yielding new TDs generation [10-12]. It is possible that the decrease of oxygen-vacancy defects at $800^{\circ} \mathrm{C}$ (Figure 5) is associated with $\mathrm{O}_{\mathrm{i}}$ atoms emission, which means that $\left[\mathrm{O}_{\mathrm{i}}\right]$ increases but we find experimentally low $\left[\mathrm{O}_{\mathrm{i}}\right]$ for $\mathrm{Cz}-\mathrm{Si}$ samples heat treated at temperatures greater than $550^{\circ} \mathrm{C}$ (inset of Figure 5). This work shows that both $\mathrm{O}_{\mathrm{i}}$ and $\mathrm{O}_{2 \mathrm{i}}$ contribute to the formation of late TDs. Hence, more than one reaction is envisaged for the formation of larger oxygen chains [11] and oxygen-vacancy

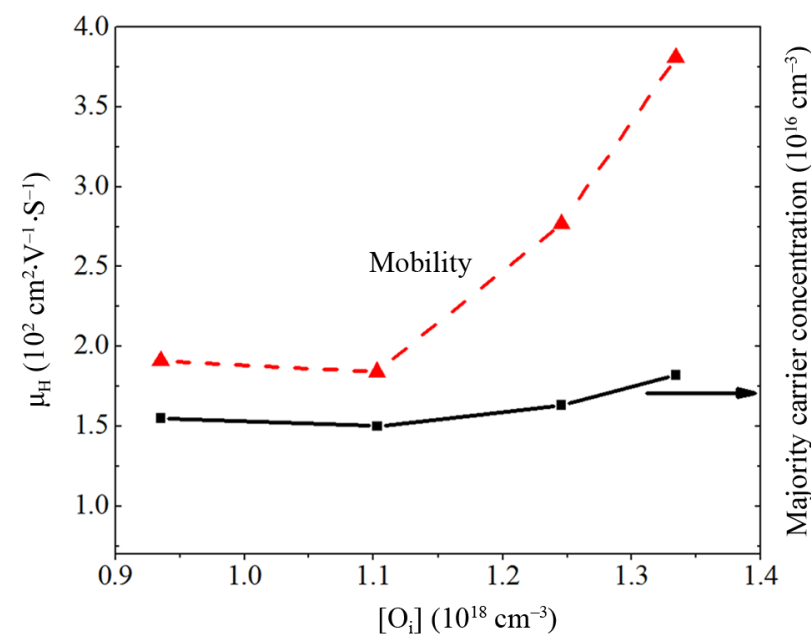

Figure 3. Dependence of the mobility and the majority carrier concentration on interstitial oxygen concentration in boron doped $\mathrm{Cz}-\mathrm{Si}$.

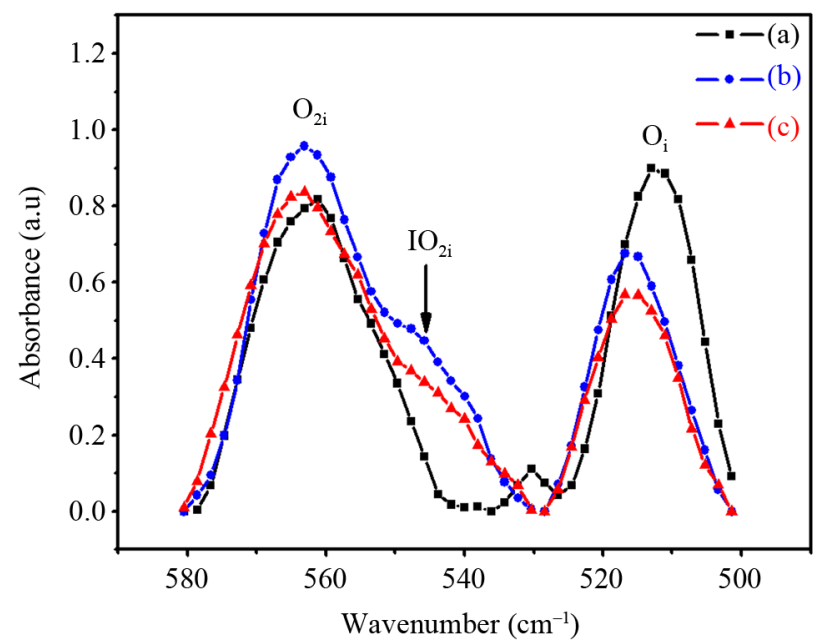

Figure 4. Room temperature IR absorption spectra for: as-grown Si sample (a) heat treated at $450^{\circ} \mathrm{C}$ (b) and $800^{\circ} \mathrm{C}$ (c) both during $4 \mathrm{~h}$. In this spectral range oxygen dimer formation compete well with the loss of oxygen atoms at high temperatures. 
defects $\left(\mathrm{VO}_{4}\right)$ favoring the generation of TDs [13]. Several models of TDs have been suggested, but their configurations are not yet well known. Si-O moleculechains developing at $450^{\circ} \mathrm{C}$ and then forming oxygen clustering is one of the configurations that have been suggested $[11,12]$.

In the following, we try correlating TDs' behavior with the resistivity of the Si samples using the four-point probe technique. Figure 7 shows the variation of the resistivity as a function of $\left[\mathrm{O}_{\mathrm{i}}\right]$ in $\mathrm{Cz}-\mathrm{Si}$ samples submitted to annealing at $450^{\circ} \mathrm{C}$ and subsequent heat treatment at $800^{\circ} \mathrm{C}$ under $\mathrm{N}_{2}$ ambient. The increase of the resistivity after thermal annealing at $450^{\circ} \mathrm{C}$ may be attributed to clustering of oxygen atoms considered as more electrically active TDs at this temperature [11].

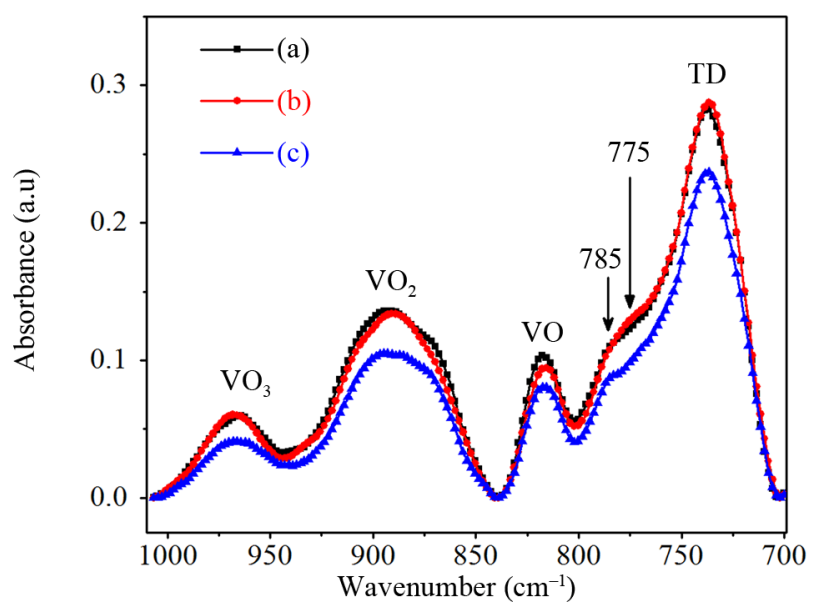

Figure 5. Room temperature FTIR spectra describing the progress of $\mathrm{O}_{\mathrm{i}}, \mathrm{VO}_{\mathrm{n}}$ and $\mathrm{TDs}$ absorption bands for as-grown sample (a) heat treated at $450^{\circ} \mathrm{C}$ (b) and subsequently at $800^{\circ} \mathrm{C}$ (c) during $4 \mathrm{~h}$. The inset shows the effect of annealing on the main IR absorption band of interstitial oxygen appearing at around $1100 \mathrm{~cm}^{-1}$.

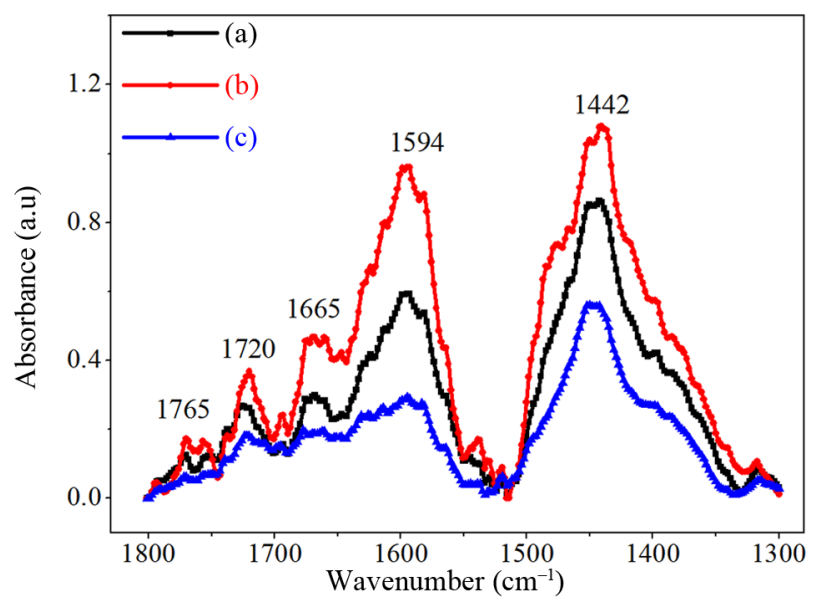

Figure 6. Room temperature absorption spectra of as-grown sample (a) heat treated at $450^{\circ} \mathrm{C}$ (b) and subsequently annealed at $800^{\circ} \mathrm{C}$ (c) both during $4 \mathrm{~h}$. It shows the relative disappearance of the IR bands at $1665 \mathrm{~cm}^{-1}, 1720 \mathrm{~cm}^{-1}$ and $1765 \mathrm{~cm}^{-1}$ upon successive annealing at $800^{\circ} \mathrm{C}$.

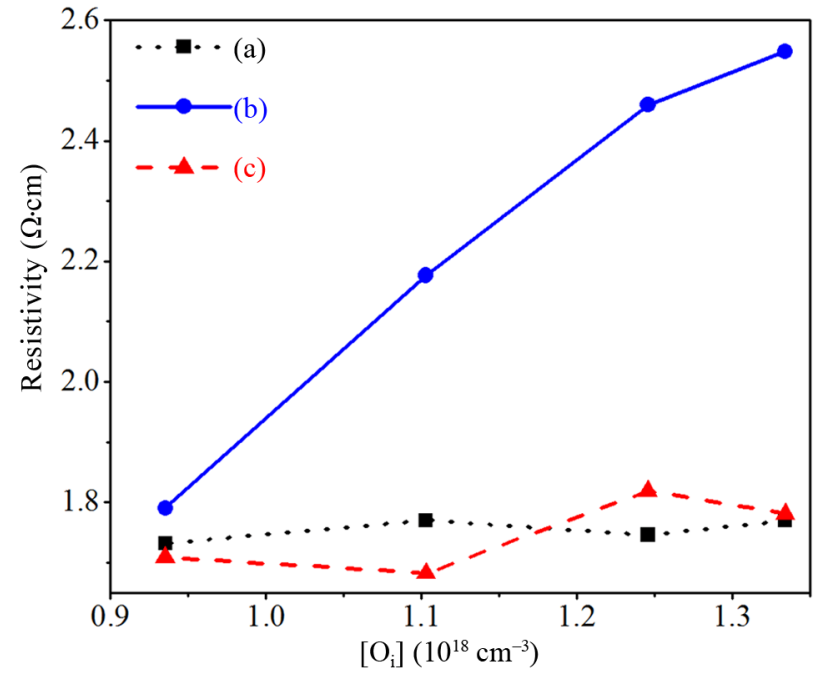

Figure 7. Variation of the resistivity with the concentration of interstitial oxygen for as-grown c-Si wafers (a) after thermal treatment at $450^{\circ} \mathrm{C}$ (b) and $800^{\circ} \mathrm{C}$ (c) during 4 hours under $\mathrm{N}_{2}$ ambient.

The generation of TDs is strongly dependent on the initial concentration of oxygen, and annealing temperature and duration.

It should be mentioned that oxygen aggregation at $800^{\circ} \mathrm{C}$ in the pre-annealed samples is accompanied by an effective generation of new thermal donors [14]. The increase of the resistivity to about $2.6 \Omega \cdot \mathrm{cm}$ (Figure 7) is due to TDs activation after heat treatment at $450^{\circ} \mathrm{C}$ and the resistivity recovers its initial values following annealing at $800^{\circ} \mathrm{C}$. Independently on interstitial oxygen concentration (Figure 7), an increase in annealing temperature $\left(800^{\circ} \mathrm{C}\right)$ reduce the donor concentration, which in turn lead to an increase of the hole concentration and a reduction of the resistivity. This phenomenon can be explained by proposing that the addition of further oxygen atoms to the core of the electrically active clusters neutralized its electrical activity.

\subsection{Discussions}

It seems to be clear that the formation of TDs is slightly dependent on $\left[\mathrm{O}_{\mathrm{i}}\right]$. However, IR absorption bands in the $600-400 \mathrm{~cm}^{-1}$ (Figure 4) and $300-700 \mathrm{~cm}^{-1}$ (Figure 6) spectral ranges, clearly reveal that even under the cool down process, the generation of TDs is strongly mediated by the formation of vacancies.

During annealing at $450^{\circ} \mathrm{C}$, the first stage of oxygen aggregation is the formation of $\mathrm{O}_{2 \mathrm{i}}$ dimer in materials containing quite high concentrations of $\mathrm{O}_{\mathrm{i}}$ atoms. Any $\mathrm{O}_{\mathrm{i}}$ atom can be trapped by any other $\mathrm{O}_{\mathrm{i}}$ but the loss of $\mathrm{O}_{\mathrm{i}}$ atoms due to trapping by carbon or other impurity atoms (contamination) at concentration less than $10^{16} \mathrm{~cm}^{-3}$ is negligible; this was checked taking into account the results 
of the electronic grade Cz-silicon. It has been theoretically shown that the IR absorption bands related to interstitial oxygen and different point defects including oxygen in combination with vacancy-defects increase in vibrational frequency due to ${ }^{18} \mathrm{O}-{ }^{16} \mathrm{O}$ isotopic effect $[15,16]$. However, in this work, we experimentally find that only the interstitial oxygen band of the asymmetric stretching mode appearing at $512 \mathrm{~cm}^{-1}$ shows a small shift of about $5 \mathrm{~cm}^{-1}$ upon annealing at $450^{\circ} \mathrm{C}$ (Figure 4). Basically, the formation of the interstitial-oxygen defect, exhibiting an IR mode at $545 \mathrm{~cm}^{-1}$ (Figure 4), is associated with the enhancement of the IR intensity relative to oxygen dimer in the staggered configuration. As the annealing temperature rise up to $800^{\circ} \mathrm{C}$, one may observe that the intensity of the $566 \mathrm{~cm}^{-1}, 545 \mathrm{~cm}^{-1}$, and $517 \mathrm{~cm}^{-1}$ IR bands corresponding to oxygen pairs, A center and interstitial oxygen, respectively, decrease slowly. A noticeable decrease of the IR absorption band relative to interstitial oxygen at $1100 \mathrm{~cm}^{-1}$ occurs while the sample is submitted to annealing at $450^{\circ} \mathrm{C}$ and subsequent heat treatment at $800^{\circ} \mathrm{C}$ (Figure 5). However, all oxygen-vacancy IR absorption bands decrease without any shift to higher frequencies.

Obviously, the formation of dimer, oxygen-vacancy, interstitial-oxygen defects and TDs, depend on the thermal history of the wafers more than on interstitial oxygen concentration in $\mathrm{Cz}-\mathrm{Si}[17,18]$. The dissociation rate of dimer is likely to increase as the annealing temperature increases so that the measured values of $\left[\mathrm{O}_{\mathrm{i}}\right]$ (after heating) is expected to increase (Figure 4) when avoiding the precipitation. Similar results and behaviors were observed in electronic grade $\mathrm{Cz}$-Silicon. When, the annealing temperature rises and reaches $800^{\circ} \mathrm{C}, \mathrm{SiO}_{2}$ clusters begin to form. In fact, as the annealing step proceeds a change in the precipitation kinetics may occur, moving from microscopic clusters to macroscopic ones (precipitation). For high annealing temperature, the loss of interstitial oxygen is probably mediated by the formation of $\mathrm{VO}_{\mathrm{n}}$, which may have more than three interstitial oxygen atoms, and the formation of new TDs as revealed from resistivity measurements. The precipitation of oxygen atoms well competes with the formation of new TDs, a recovery of the initial resistivity and a slight enhancement of the majority charge carriers mobility (Table 1) is in good agreement with this assumption.

Table 1. The effect of oxygen TDs and A-center on mobility of majority charge carriers of samples taken from the edge and the center of a $\mathrm{Cz}$-silicon wafer after thermal treatment at $450^{\circ} \mathrm{C}$ and $800^{\circ} \mathrm{C}$ during 4 hours under nitrogen $\left(\mathrm{N}_{2}\right)$.

\begin{tabular}{ccc}
\hline Ingot relative position & Edge & Centre \\
\hline$\mu_{\mathrm{H}}$ without thermal treatment $\left(\mathrm{cm}^{2} \cdot \mathrm{V}^{-1} \cdot \mathrm{s}^{-1}\right)$ & 270 & 340 \\
$\mu_{\mathrm{H}}$ formation of TDs at $450^{\circ} \mathrm{C}\left(\mathrm{cm}^{2} \cdot \mathrm{V}^{-1} \cdot \mathrm{s}^{-1}\right)$ & 140 & 180 \\
$\mu_{\mathrm{H}}$ after annihilation of TDs at $800^{\circ} \mathrm{C}\left(\mathrm{cm}^{2} \cdot \mathrm{V}^{-1} \cdot \mathrm{s}^{-1}\right)$ & 370 & 440 \\
\hline
\end{tabular}

\section{Summary and Conclusions}

At $450^{\circ} \mathrm{C}$, oxygen aggregation was found to be limited by the increase of dimer $\left(\mathrm{O}_{2 \mathrm{i}}\right)$ concentration and the formation of new oxygen defect assigned to interstitial-dioxygen center with an IR vibration mode locating at 545 $\mathrm{cm}^{-1}$. These changes induce a noticeable intensity decrease of the $512 \mathrm{~cm}^{-1}$ absorption band with a $5 \mathrm{~cm}^{-1}$ shift to $517 \mathrm{~cm}^{-1}$ explained by an isotopic effect of ${ }^{18} \mathrm{O}-{ }^{16} \mathrm{O}$ nature. Moreover, it is shown that after annealing at $450^{\circ} \mathrm{C}$, the $\mathrm{VO}, \mathrm{VO}_{2}$ and $\mathrm{VO}_{3}$ complexes are stable (no frequency shifts were observed) and various absorption modes are prevailing in the of $1800-1300 \mathrm{~cm}^{-1}$ range.

Consecutive heat treatments at $800^{\circ} \mathrm{C}$ show that additional oxygen atoms are linked to the core of the predominantly clusters formed at $450^{\circ} \mathrm{C}$. This leads to partial annihilation of TDs and decrease of the intensity of the $\mathrm{O}_{\mathrm{i}}$ and oxygen-vacancy defects related IR bands. The resistivity recovers similar values as that for as-grown wafers; however the majority charge carrier mobility is improved. This indicates that some active oxygen-related defects are passivated following annealing at $800^{\circ} \mathrm{C}$. Heat treatments at elevated temperatures $\left(>500^{\circ} \mathrm{C}\right)$ lead to a competition between formation and annihilation of TDs and a systematic study is of great importance to claim the kinetics of TD generation and passivation.

\section{Acknowledgements}

The authors would like to gratefully thank the Tunisian Ministry of Higher Education and Scientific Research for the financial support.

\section{REFERENCES}

[1] W. Götz, G. Pensl and W. Zulehner, "Observation of Five Additional Thermal Donor Species TD12 to TD16 and of Regrowth of Thermal Donors at Initial Stages of the New Oxygen Donor Formation in Czochralski-Grown Silicon," Physical Review B, Vol. 46, No. 7, 1992, pp. 4312-4315. doi:10.1103/PhysRevB.46.4312

[2] M. Pesola, J. von Boehm, T. Mattila and R. Nieminen, "Computational Study of Interstitial Oxygen and Vacancy-Oxygen Complexes in Silicon," Physical Review B, Vol. 60, No. 16, 1999, pp. 11449-11463. doi:10.1103/PhysRevB.60.11449

[3] J. Coutinho, R. Jones, P. R. Briddon and S. Öberg, "Oxygen and Dioxygen Centers in Si and Ge: DensityFunctional Calculations," Physical Review B, Vol. 62, No. 16, 2000, pp. 10824-10840.

doi:10.1103/PhysRevB.62.10824

[4] W. M. Bullis, M. Watanabe, A. Baghdadi, Y. Z. Li, R. I. Scace, R. W. Series and P. Stallhofer, "Semiconductor Silicon/1986," In: H. R. Huff, T. Abe and B. Kolbesen, Eds., The Electrochemical Society Softbound Proceedings Series, The Electrochemical Society, Pennington, 1986, p. 
166.

[5] M. Pesola, J. von Boehm and R. Nieminen, "Vibrations of the Interstitial Oxygen Pairs in Silicon," Physical Review Letter, Vol. 82, No. 20, 1999, pp. 4022-4025. doi:10.1103/PhysRevLett.82.4022

[6] W. Götz, G. Pensl, W. Zulehner, R. Newman and S. McQuaid, "Thermal Donor Formation and Annihilation at Temperatures above $500{ }^{\circ} \mathrm{C}$ in Czochralski-Grown Si," Journal of Applied Physics, Vol. 84, No. 7, 1998, pp. 3561-3568.

[7] J. Lindström, T. Hallberg, J. Hermansson, L. Murin, B. Komarov, V. Markevich, M. Kleverman and B. G. Svensson, "Interaction between Self-Interstitials and the Oxygen Dimer in Silicon," Physica B, Vol. 308-310, 2001, p. 284. doi:10.1016/S0921-4526(01)00694-9

[8] D. Aberg, B. Svensson, T. Hallberg and J. Lindström, "Kinetic Study of Oxygen Dimer and Thermal Donor Formation in Silicon," Physical Review B, Vol. 58, No. 19, 1998, pp. 12944-12951. doi:10.1103/PhysRevB.58.12944

[9] L. Murin, T. Hallberg, V. Markevich and J. Lindström, "Experimental Evidence of the Oxygen Dimer in Silicon," Physical Review Letter, Vol. 80, No. 1, 1998, pp. 93-96. doi:10.1103/PhysRevLett.80.93

[10] Y. J. Lee, J. von Boehm and R. M. Nieminen, "Simulation of the Kinetics of Oxygen Complexes in Silicon," Physical Review B, Vol. 66, No. 16, 2002, pp. 165221165232. doi:10.1103/PhysRevB.66.165221

[11] Y. J. Lee, J. von Boehm, M. Pesola and R. Nieminen, "First Principles Study of Migration Restructuring, and Dissociation Energies of Oxygen Complexes in Silicon," Physical Review B, Vol. 65, No. 8, 2002, Article ID: 085205. doi:10.1103/PhysRevB.65.085205

[12] Y. J. Lee, J. von Boehm, M. Pesola and R. Nieminen,
"Comparison of Oxygen-Chain Models for Late Thermal Double Donors in Silicon," Applied Physics Letter, Vol. 82, No. 13, 2003, pp. 2094-2096. doi:10.1063/1.1563813

[13] L. Murin, J. Lindström, V. Markevich, A. Misiuk and C. Londos, "Thermal Double Donor Annihilation and Oxygen Precipitation at around $650^{\circ} \mathrm{C}$ in Czochralski-Grown Si: Local Vibrational Mode Studies," Journal of Physics: Condensed Matter, Vol. 17, 2005, pp. 2237-2246. doi:10.1088/0953-8984/17/22/011

[14] O. Prakash, N. Upreti and S. Singh, "Behaviour of Oxygen in CZ-Silicon during $430^{\circ} \mathrm{C}-630^{\circ} \mathrm{C}$ Heat Treatment," Materials Science and Engineering B, Vol. 52, No. 2-5, 1998, pp. 180-184.

[15] M. Pesola, J. von Boehm and R. Nieminen, "Structures of Thermal Double Donors in Silicon," Physical Review Letters, Vol. 84, No. 23, 2000, pp. 5343-5346. doi:10.1103/PhysRevLett.84.5343

[16] S. Öberg, C. Ewels, R. Jones, T. Hallberg, J. Lindström, L. Murin and P. R. Briddon, "First Stage of Oxygen Aggregation in Silicon: The Oxygen Dimer," Physical Review Letter, Vol. 81, No. 14, 1998, pp. 2930-2933. doi:10.1103/PhysRevLett.81.2930

[17] V. V. Voronkov and R. Falster, "Latent Complexes of Interstitial Boron and Oxygen Dimers as a Reason for Degradation of Silicon-Based Solar Cells," Journal of Applied Physics, Vol. 107, No. 5, 2010, pp. 53509-53520. doi:10.1063/1.3309869

[18] L. I. Murin, E. A. Tolkacheva, V. P. Markevich, A. R. Peaker, B. Hamilton, E. Monakhov, B. G. Svensson, J. L. Lindström, P. Santos, J. Coutinho and A. Carvalho, "The Oxygen Dimer in Si: Its Relationship to the Light-Induced Degradation of Si Solar Cells?" Applied Physics Letters, Vol. 98, No. 18, 2011, pp. 182101-182103. doi: $10.1063 / 1.3584138$ 